Research Article

\title{
Stochastic Constitutive Relationship of Self-Compacting Concrete under Uniaxial Compression
}

\author{
Xiao Li, ${ }^{1,2}$ Zhi Shan $\mathbb{D}^{1,2}$ Zhiwu Yu, ${ }^{1,2}$ Jing Gao $\mathbb{D}^{1,2}$ and Jianfeng Mao ${ }^{1,2}$ \\ ${ }^{1}$ School of Civil Engineering, Central South University, 68 South Shaoshan Road, Changsha 410004, China \\ ${ }^{2}$ National Engineering Laboratory for High Speed Railway Construction, Changsha 410004, China \\ Correspondence should be addressed to Zhi Shan; zhishan@csu.edu.cn
}

Received 23 July 2018; Revised 19 September 2018; Accepted 24 September 2018; Published 23 October 2018

Academic Editor: Shazim A. Memon

Copyright (c) 2018 Xiao Li et al. This is an open access article distributed under the Creative Commons Attribution License, which permits unrestricted use, distribution, and reproduction in any medium, provided the original work is properly cited.

\begin{abstract}
Experimental investigations on self-compacting concrete (SCC) under uniaxial monotonic and cyclic compression taking into account the stochastic constitutive relationship were reported and conducted. By introducing a practical method on plasticity characterization into the fiber bundle-plastic chain model, a new constitutive model based on the statistic damage approach for describing the stochastic mechanical responses of SCC under uniaxial compression was proposed. The comparison between the experimental results and the predictions demonstrated that the proposed model was able to characterize the salient features for SCC under both uniaxial monotonic and cyclic compression. Furthermore, the stochastic evolution (SE) of SCC under uniaxial compression and a comparison between the SCC and normally vibrated concrete (NVC) in certain aspects were analyzed and discussed; it was concluded that the stochastic constitutive relationship of SCC under compression can be understood by a media process of transition from microscale to macroscale.
\end{abstract}

\section{Introduction}

Cement concrete is widely used in railway, bridges, and buildings due to its excellent mechanical performance on the aspects of bearing capacity, durability, and other mechanical properties. During the preceding decades, a variety of essential topics associated with the mechanical properties of cement concrete have been well studied by researchers and practitioners. Among those topics, the stochastic mechanical behavior of cement concrete has received strong attention due to its uncertain effects on the structural optimization and safety control.

Recently, a new type of high performance concrete named self-compacting concrete (SCC) is developed and increasingly implemented in the construction industries due to its inherent advantages of high fluidity, good segregation resistance, and distinctive self-compacting ability [1]. Specifically, during the pouring process, SCC is capable of flowing through and fill gaps of reinforcement and corners of moulds and requiring no external vibration and compaction, with excellent homogeneity and presenting no segregation [2-4]. To date, a variety of celebrated works have been conducted on relevant topics of SCC, and the details are illustrated as follows.

Initially, in the current literature, researches topics of SCC on two major categories are found to be mostly emphasized: the fresh performances and the hardened properties. In detail, for the topic of fresh performances, the flow ability, passing ability, and segregation resistance were comprehensively studied by several researchers [2-4]. With regards to the topic of hardened properties, a number of studies focusing on the mechanical properties including the compressive strength, tensile strength, and elastic modulus were proposed [5-10]. However, compared with normallyvibrated concrete (NVC), the number of studies on the hardened properties of SCC is quite limited, which results in that the sections in most guidelines [11-13] are usually relatively brief.

Additionally, among the aforementioned studies of SCC in the literature [5-10], few results are available 
incorporating the stochastic mechanic properties under compression. For example, Brouwers and Radix [9] conducted a series of statistical analyses on the compressive strength and splitting tensile strength of SCC; Filho et al. developed several statistical models for characterizing the compressive strength, splitting tensile strength, and elastic modulus of SCC; similarly, the other works were also only limited on the investigations on the deterministic properties of SCC, e.g., the deterministic compressive/tensile strength [5-8], elastic modulus $[5,6]$, constitutive relationship under compression [7], and fracture property [8].

However, during the mechanical modelling of the materials, the stochastic constitutive relationship is able to characterize the randomness of material's mechanical behaviors, e.g., the different nonlinearity stress-strain responses exhibited in independent samples of same material. Concretely, for SCC, the causes for such randomness can be mainly attributed to its complex inhomogeneous microstructure, due to the irregular shape, random size and distribution of aggregates [14], the sedimentation of cement particles [15], the accumulation of pore water [15], the curing conditions-induced undetermined hydration [16], the different location of the concrete in the structures [17], and the varied skill of the workers [10]. Although SCC generally possesses a more homogeneous microstructure with a lower water accumulation around aggregated and a lower porosity in the interfacial transition zone (ITZ) than that of the normally vibrated concrete (NVC) $[5,14,18]$, the stochastic constitutive relationship is still necessary to be taken into account during relevant designing and analyzing process. The design and analysis of structures by considering its stochastic response using relevant data $[19,20]$ enables us to gain several more comprehensive and useful information to characterize the structure performance.

Furthermore, quasibrittle materials like SCC are heterogeneous materials with random pre-existing flaws. During the loading process, these flaws cause the development of local stresses and further result in the development of both damage/fracture and plasticity in a stochastic way. Therefore, the damage and plasticity are concluded as the two main factors governing the materials' stochastic constitutive relationship. Recently, a convenient statistical damage model named fiber bundle-plastic chain model (BCM) [20] is proposed and verified to be a convenient and visual approach to the random nature and stochastic behaviors considering both damage and plasticity. Compared with other theoretical models developed over a few decades, the BCM has the advantages in the effectiveness on characterizing both the stochastic continuous damage and plastic behaviors for quasibrittle materials during the loading process. Figure 1 illustrates that BCM is able to predict the stochastic properties of microstructure (the probability density of micro-yielddamage of concrete (Figure 1(b)), which agrees with the energy dissipation results from the acoustic emission test (AE, Figure 1(c)) and the probability density results of hardness modulus obtained in the nanoindentation test (Figure 1(d)).
Therefore, the main objective of this work is to investigate on the stochastic constitutive relationship of SCC experimentally by utilizing the uniaxial monotonic and cyclic compression tests and further develop an analytical model based on the BCM that can effectively predict the stochastic constitutive relationship of SCC. With this objective, the remainder of this work is organized as follows. In Section 2, the materials and experimental methods in this work are firstly introduced, then the experimental results are investigated by examining the mean value and the standard variation (STD) of the stressstrain curves of SCC under uniaxial monotonic compression tests, and the plasticity development of SCC under uniaxial cyclic compression tests, respectively. In Section 3, after a brief recall of the BCM, an analytical model for predicting the stochastic constitutive relationship of SCC is developed by introducing a practical method on the plasticity characterization into the BCM, and the effectiveness of the proposed model is also verified by comparison between the predictions and the experimental results. It is then followed by Section 4 where the transition process from microscale to macroscale for SCC under compression, and the comparisons of the constitutive relationships between SCC and typical NVCs are analyzed and discussed. The conclusions of this work are finally given in Section 5.

\section{Experimental Study and Results}

2.1. Materials and Methods. In order to investigate the stochastic constitutive relationships for SCC under both uniaxial monotonic and cyclic compressive loading, a total sixteen SCC samples are considered with a mixture ratio according to the technical specification in China [21]. The mixture ratio for the SCC is determined as cement: fly ash : mineral powder: expanding agent: sand:aggregate: water: admixture = 331:108:64:48:824:823:177:5.5 (unit: $\mathrm{kg} / \mathrm{m}^{3}$ ). In detail, the cement is Portland cement of P.II $42.5 \mathrm{R}$, the water is the tap water, the aggregates are crushed limestone with diameters of approximately $5 \sim 20 \mathrm{~mm}$, the sands are the middle grain sands, the mineral admixtures are the mineral powder of $\mathrm{S} 95$ and fly ash, and the admixture is the water-reducing agent of NoF-II.

The workability of SCC was tested after the technical specification [21] and is listed in Table 1 which meets the relative requirements.

The dimensions of the SCC samples were designed as $100 \times 100 \times 300 \mathrm{~mm}^{3}$. For both uniaxial monotonic and cyclic compression tests, eight SCC samples were utilized (Figure 2(a)), respectively. In addition, prior to the compression tests, six samples were tested according to the code [22] for determining the elastic modulus $E_{0}$ and the mean compressive strength $f_{\mathrm{cm}}$ of the SCC samples, and the results were determined as $E_{0}=25.58 \mathrm{GPa}$ and $f_{\mathrm{cm}}$ $=34.13 \mathrm{MPa}$.

Both the uniaxial monotonic and cyclic compression tests were carried out according to the code [22] in a closedloop servo-controlled compression test machine. The strains/deformations of each specimen were monitored by 


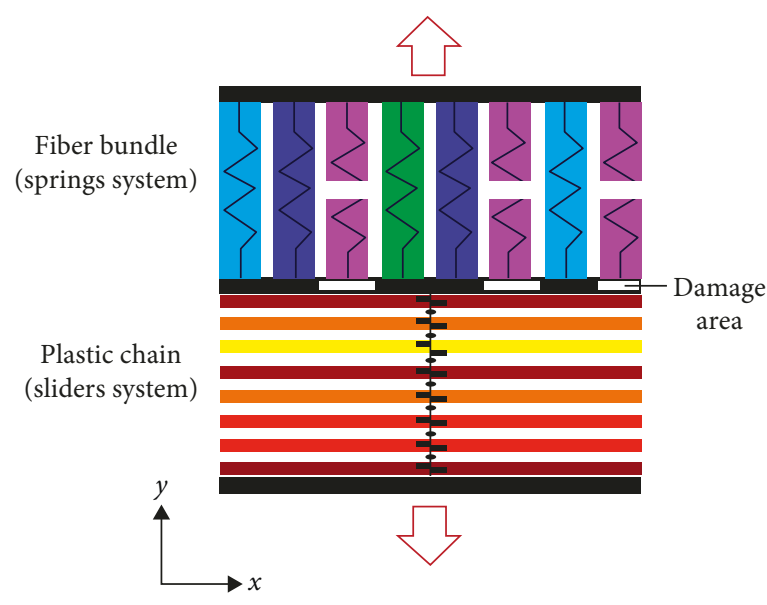

(a)

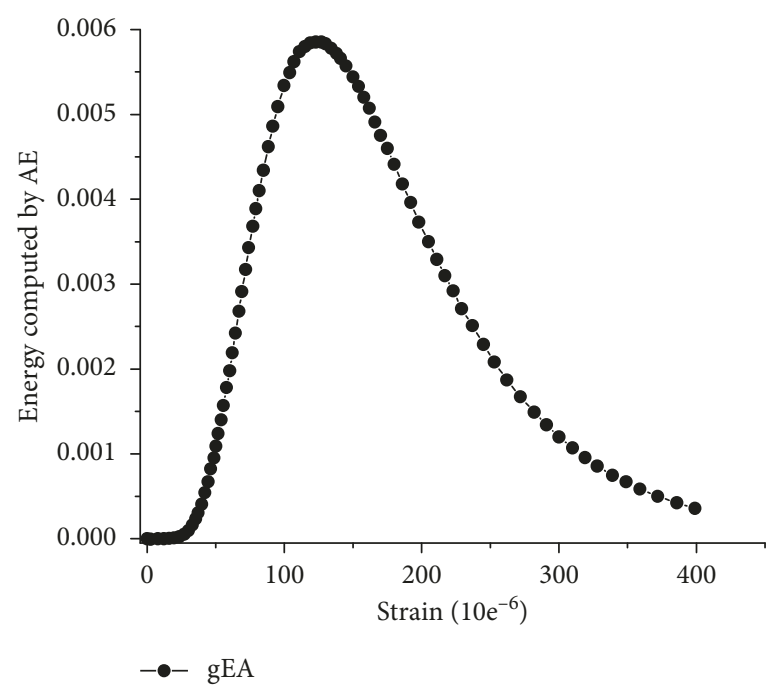

(c)

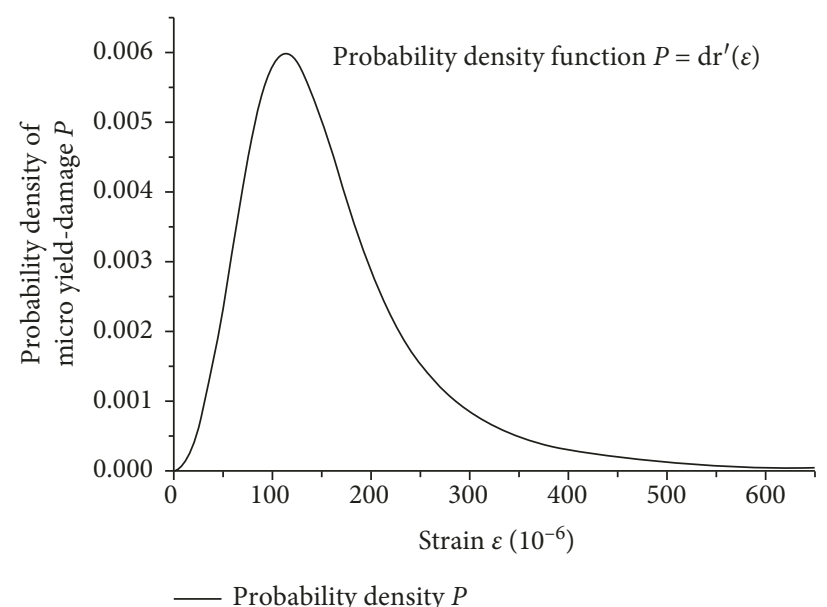

(b)

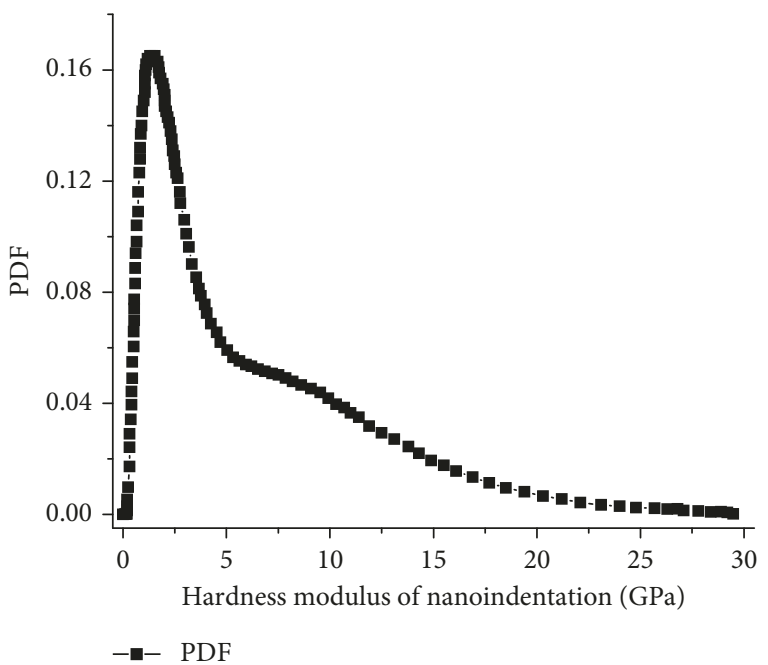

(d)

FIGURE 1: Fiber bundle-plastic chain model (BCM) [20] (a) and its typical predicted probability density of micro-yield-damage $P$ [20] (b), comparing with the energy computed by acoustic emission (AE) $g_{\mathrm{EA}}$ [19] (c) and the probability density of hardness modulus of nanoindentation PDF [19] (d).

TABLE 1: Workability test results of SCC.

\begin{tabular}{lcccc}
\hline Test & $\begin{array}{c}\text { Slump } \\
\text { flow } \\
S_{\mathrm{f}}(\mathrm{mm})\end{array}$ & $\begin{array}{c}\text { Slump } \\
\text { time } \\
T_{50}(\mathrm{~s})\end{array}$ & $\begin{array}{c}\text { Height of } \\
\text { J-ring7 } H_{\mathrm{J}} \\
(\mathrm{mm})\end{array}$ & $\begin{array}{c}\text { Height ratio of L-box } \\
H_{2} / H_{1}\end{array}$ \\
\hline Result & 650 & 4.5 & 15 & 0.9 \\
\hline
\end{tabular}

using both the electrical resistance strain gauges with a resolution of $1 \mu \varepsilon$ and the extensometer (Figure $2(\mathrm{~b})$ ).

\subsection{Experimental Results}

2.2.1. Results of Monotonic Compression Test. The stressstrain curves and the enveloping region of total eight samples obtained from the uniaxial monotonic compression test are plotted in Figures 3(a) and 3(b), respectively. The mean stress $\bar{\sigma}(\varepsilon)$ and its standard deviation $\operatorname{STD}(\varepsilon)$ for a certain strain value can be calculated by Equations (1) and
(2), which the resulted mean stress-strain curve and the standard deviation curve are plotted in Figure 3(c).

$$
\bar{\sigma}(\varepsilon)=\frac{1}{N} \sum_{i=1}^{N} \sigma_{i}(\varepsilon)
$$

$$
\operatorname{STD}(\varepsilon)=\sqrt{\frac{1}{N-1} \sum_{i=1}^{N}\left[\sigma_{i}(\varepsilon)-\bar{\sigma}(\varepsilon)\right]^{2}}
$$

where $\bar{\sigma}(\varepsilon)$ and $\operatorname{STD}(\varepsilon)$ denote the mean stress and the standard deviation corresponds to the strain $\varepsilon$, respectively, $N$ denotes the total number of stress-strain curves, and $\sigma_{i}(\varepsilon)$ denotes the stress corresponds to the strain $\varepsilon$ in $i$ th stressstrain curve.

It is observed from the experimental results that the SCC shows apparent stochastic responses during the uniaxial monotonic compression test. In Figure 3(a), it is 


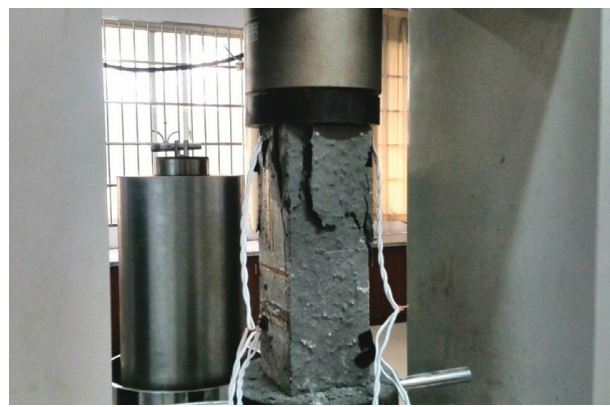

(a)

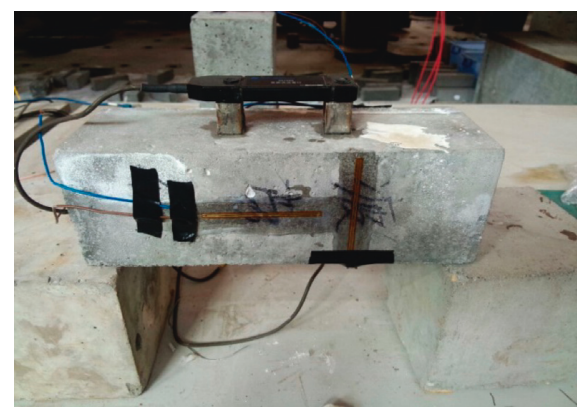

(b)

Figure 2: Experimental setup. (a) A prism concrete specimen is subjected to directly compression. (b) The layout of the electrical resistance strain gauges and the extensometer.

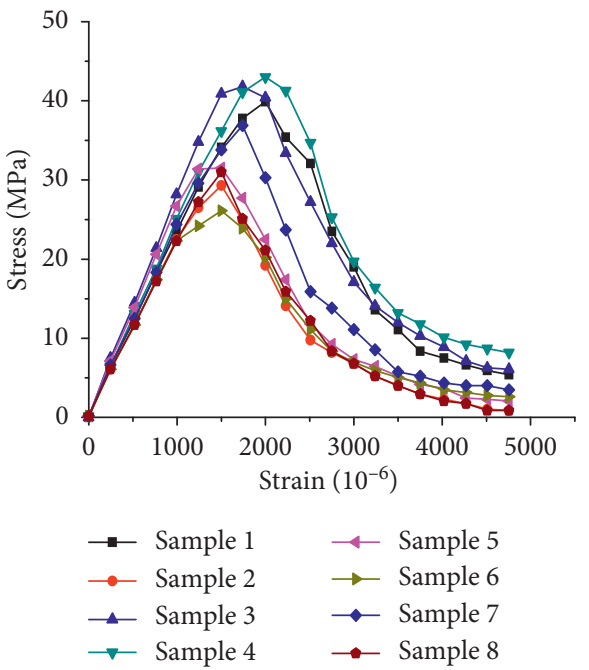

(a)

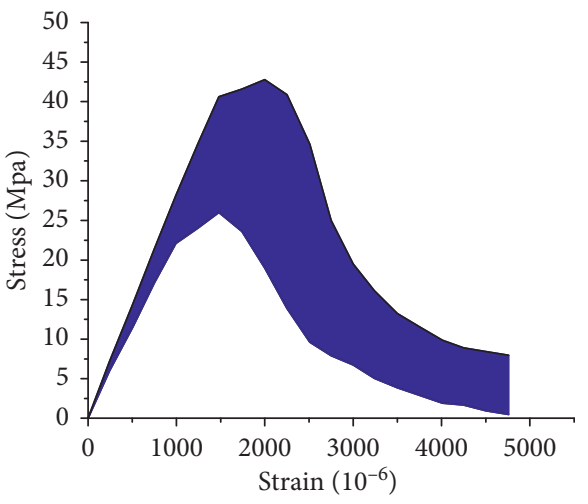

Enveloping region of experimental results

(b)

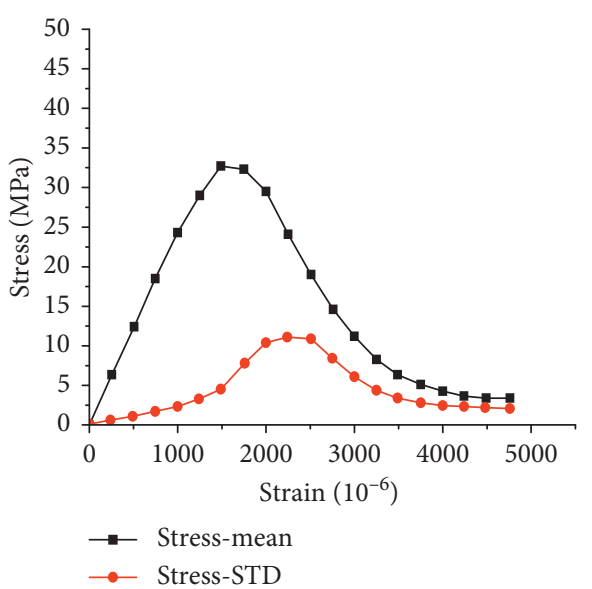

(c)

FIGURE 3: Experimental results of SCC samples under monotonic compressive loads. (a) $\sigma-\varepsilon$ curves. (b) Enveloping region of $\sigma-\varepsilon$. (c) Mean and STD of $\sigma-\varepsilon$.

found that the peak stresses in the stress-strain curves of the eight SCC samples are varied from approximately $25 \mathrm{MPa}$ to $43 \mathrm{MPa}$, with corresponding strains ranged from approximately $1500 \times 10^{-6}$ to $2000 \times 10^{-6}$. In Figure 3(b), it is observed that, in the ascending branch, the area enveloped by the eight stress-strain curves is less than that in the descending postpeak (softening) branch, which reveals for the stochastic responses of SCC, and a smaller variation level is obtained during the earlier loading stage. In Figure 3(c), the peak stress $\sigma_{\mathrm{p}}$ in the mean stress-strain curve is $32.76 \mathrm{Mpa}$ with 
a corresponding strain of $1501 \times 10^{-6}$, and the residual stress $\sigma_{\mathrm{s}}$ is found to be around 3.36 MPa. Moreover, in the standard deviation curve, the peak stress is $11.03 \mathrm{Mpa}$ with a corresponding strain of $2234 \times 10^{-6}$. It is noteworthy that, in the standard deviation curve, the strain corresponding to the peak point is significantly larger than that in the mean stress-strain curve.

2.2.2. Results of Cyclic Compression Test. The results of the cyclic compression tests for eight SCC samples are displayed in Figure 4. In order to avoid the complexity for exhibiting the massive data with the presence of the hysteretic loops, only one typical load-displacement curve (sample 1) obtained from the tests is plotted in Figure 4(a) for presenting the general response of SCC under cyclic compression loading. Alternatively, the relationships between the plastic strain and the total strain for the eight SCC samples during the tests are plotted in Figure 4(b). Furthermore, by applying the method for characterizing the plasticity development proposed in the literature $[23,24]$, the stochastic plasticity behaviors for SCC can be illustrated in terms of the reciprocal of the plastic variable $r$ as a function of the plasticdamage variable $d r$ defined in Equations (3) and (4) proposed by the literature [20].

$$
\begin{aligned}
& d r=1-\frac{\sigma}{E_{0} \varepsilon}, \\
& r=\frac{\varepsilon_{\mathrm{p}}}{\varepsilon},
\end{aligned}
$$

where $\sigma$ denotes Cauchy stress, $\varepsilon$ denotes the total strain, $E_{0}$ denotes the initial Young's modulus, and $\varepsilon_{\mathrm{p}}$ denotes the plastic strain.

Therefore, the relationships between $\varepsilon / \varepsilon_{\mathrm{p}}$ and $\varepsilon$, as well as the relationships between $1 / r$ and $d r$ for the eight SCC samples are able to be plotted in Figures 4(c) and 4(d), respectively.

In Figure 4(a), the loading-displacement envelope curve for a typical SCC sample under uniaxial cyclic compression is found to be similar to that obtained in the uniaxial monotonic test. In Figure 4(b), it is noted that the plastic strains of the eight SCC samples are accumulating nonlinearly as the increasing of the total strain. For each SCC sample, the plastic strain increases slowly at the beginning of the test while greater plastic strain accumulation is foreseen for higher total strain level. In Figure 4(c), it reveals that, as the growing of the total strain, the value of the $\varepsilon / \varepsilon_{\mathrm{p}}$ for individual SCC sample is decreasing approximately linearly. A similar development trend is followed in Figure 4(d), in which the values of $1 / r$ are plotted as a function of $d r$ for eight SCC samples. Specifically, the initial values of $1 / r$ are varied between 5.76 and 6.29 and then fall to the value about 1.38 in the course of the plastic-damage variable $d r$ increasing from 0 to 1 . To sum up, Figure 4 indicates that the plasticity of the eight SCC samples are developing in a stochastic way during the cyclic compressive loading process.

\section{Model of Stochastic Constitutive Relationship}

3.1. Brief Introduction to Fiber Bundle-Plastic Chain Model. The fiber bundle-plastic chain model (BCM) [20] is developed based on the classical fiber bundle model (FBM) for characterizing the mechanical behaviors of quasibrittle materials under external loading (Figure 1(a)). The model is considered as being consisted of a bundle of parallel linearly elastic fibers assigned with random fracture thresholds with a probability density of $P_{\mathrm{d}}(\varepsilon)$ and a chain of linked perfect plastic sliders with random yielding thresholds with a probability density $P_{\mathrm{r}}(\varepsilon)$. During the loading process, the damage propagation and the stress-driven plasticity are characterized by the continuously failure of the fibers and the yielding of the sliders.

It is noted that, after each failure event, the load of the failed fiber is equally redistributed over the intact ones in the bundle irrespective of their distance from the failure point (i.e., the equal-load sharing pattern), and a same plastic strain is produced by individual slider after each sliding event once the yielding threshold is reached.

Hence, the damage variable $d(\varepsilon)$ (i.e., the accumulative distribution of the probability density) and the plastic variable (plastic ratio) $r(\varepsilon)$ (i.e., the accumulative distribution of $\left.P_{\mathrm{r}}(\varepsilon)\right)$ is able to be calculated based on the statistical method such as

$$
\begin{aligned}
& d(\varepsilon)=\int_{0}^{\varepsilon} P_{\mathrm{d}}(\varepsilon) \mathrm{d} \varepsilon, \\
& r(\varepsilon)=\int_{0}^{\varepsilon} P_{\mathrm{r}}(\varepsilon) \mathrm{d} \varepsilon .
\end{aligned}
$$

Furthermore, in order to couple the microdamage and the plasticity for characterizing the nonlinear behavior of quasibrittle materials, a plastic-damage variable $d r(\varepsilon)$ is defined with a micro-yield-damage probability density $P(\varepsilon)$ (Figure 1(b)), thus

$$
d r(\varepsilon)=d(\varepsilon)+r(\varepsilon)=\int_{0}^{\varepsilon} P_{\mathrm{d}}(\varepsilon) \mathrm{d} \varepsilon+\int_{0}^{\varepsilon} P_{\mathrm{r}}(\varepsilon) \mathrm{d} \varepsilon=\int_{0}^{\varepsilon} P(\varepsilon) \mathrm{d} \varepsilon .
$$

Therefore, the constitutive relationship by coupling both the damage and plasticity for quasibrittle materials can be modeled as follows:

$$
\sigma=[1-d r(\varepsilon)] \cdot E_{0} \cdot \varepsilon .
$$

The plastic strain can be estimated by the following relationship:

$$
\varepsilon_{\mathrm{p}}=r(\varepsilon) \cdot \varepsilon
$$

And, the mean value $\mu(\varepsilon)$ and the standard deviations $V(\varepsilon)$ of the variables relating to the constitutive 

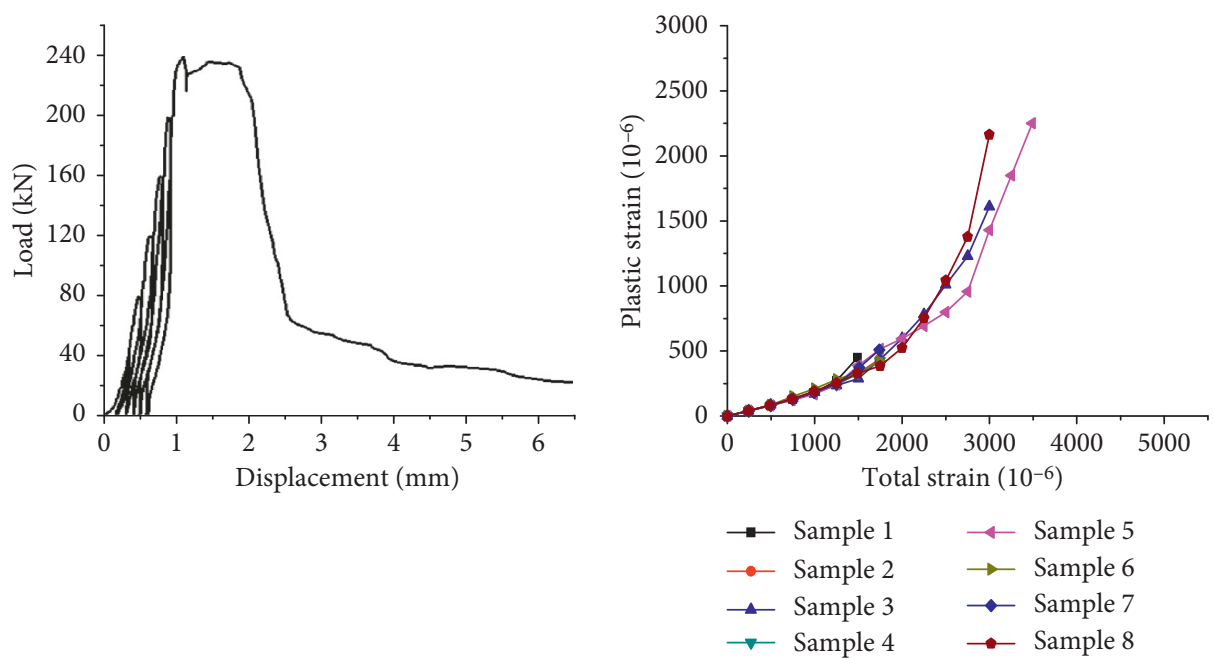

(a)

(b)

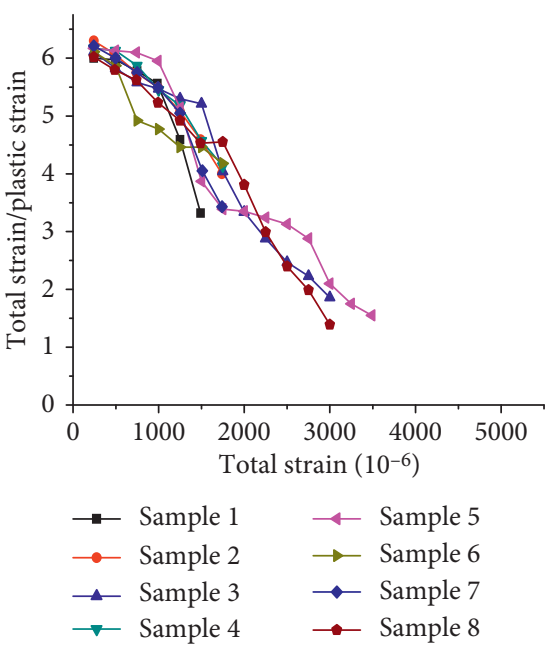

(c)

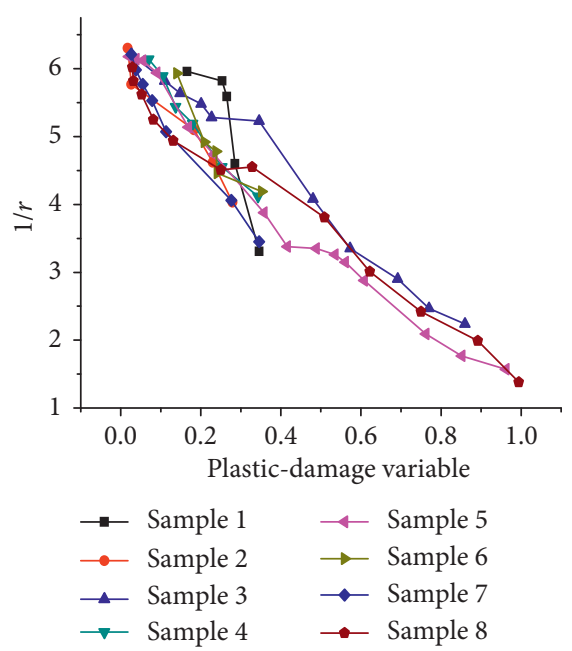

(d)

Figure 4: Experimental results of SCC samples under cyclic compression tests. (a) Typical load-displacement relationship (sample 1). (b) Relationship of $\varepsilon_{\mathrm{p}}-\varepsilon$. (c) Relationship of $\varepsilon / \varepsilon_{\mathrm{p}}-\varepsilon$. (d) Relationship of $1 / r-d r$.

relationship are characterized by the following equations, respectively:

$$
\begin{aligned}
\mu_{d r}(\varepsilon) & =E\left[\int_{0}^{\varepsilon} P(\varepsilon) \mathrm{d} \varepsilon\right]=E\left[1-\frac{\sigma_{i}}{E_{0} \varepsilon}\right], \\
V_{d r}^{2}(\varepsilon) & =E[d r(\varepsilon)]^{2}-\left[\mu_{d r}(\varepsilon)\right]^{2} \\
\mu_{\mathrm{r}}(\varepsilon) & =E\left[\int_{0}^{\varepsilon} P_{\mathrm{r}}(\varepsilon) d(\varepsilon)\right]=E\left[\frac{\varepsilon_{p, i}}{\varepsilon}\right] \\
V_{r}^{2}(\varepsilon) & =E[\mathrm{r}(\varepsilon)]^{2}-\left[\mu_{r}(\varepsilon)\right]^{2}
\end{aligned}
$$

where $i$ denotes the number of the samples.

3.2. The Analytical Model of SCC. Based on the work carried out by the literature [20], for quasibrittle materials under compression, the mean value of the plastic-damage variable $\mu_{d r}(\varepsilon)$ is expressed as follows:

$$
\mu_{d r}(\varepsilon)=\frac{A_{1}-A_{2}}{1+\left(\varepsilon / \varepsilon_{0}\right)^{p}}+A_{2},
$$

where $A_{1}, A_{2}, \varepsilon_{0}$, and $p$ denote the parameters relating to the damage/plasticity of the material due to the stochastic properties of its microstructures.

However, by fitting the experimental results of the SCC samples using the above equation form, the values of the parameters $A_{1}$ and $A_{2}$ turned out to be equal to around 0 and 1 , respectively. Thus, for simplicity, it is reasonably assumed that $A_{1}$ and $A_{2}$ are independent of the microdamage propagation and plasticity accumulation during the loading process. Therefore, in this work, $A_{1}$ is assumed to be equal to 0 and $A_{2}$ is assumed to be equal to 1 .

Hence, the mean values of plastic-damage variable $\mu_{d r}(\varepsilon)$ for SCC under compression are obtained as follows: 


$$
\mu_{d r}(\varepsilon)=1-\frac{1}{1+\left(\varepsilon / \varepsilon_{0}\right)^{p}} .
$$

In the literature [20], the standard deviation was studied in a limited way by examining the stress-strain curves for quasibrittle materials. However, for the purpose of obtaining a complete understanding on the stochastic constitutive relationship of SCC, the analysis on the standard deviation of the plastic-damage variable $\operatorname{STD}_{d r}(\varepsilon)$ is conducted by observing the results displayed in Figure 3(c), and the expression is given as follows:

$$
\operatorname{STD}_{d r}(\varepsilon)=a+b \cdot \exp \left[-\frac{1}{2} \times\left(\frac{\varepsilon-f}{c}\right)^{2}\right]
$$

where $a, b, c$, and $f$ denote the parameters relating to the variation of damage/plasticity in the material due to the size effect, considering the stochastic properties of the microstructures [25-27].

Moreover, distinguished from the complex method on the plasticity modelling in earlier work [20], a simpler method is formulated in this work by establishing the relationship between $1 / r$ and $d r$ introduced by the literature $[23,24]$.

$$
\frac{1}{\mu_{\mathrm{r}}(\varepsilon)}=g-h \cdot \mu_{d r}(\varepsilon),
$$

where $\mu_{\mathrm{r}}(\varepsilon)$ denotes the mean plastic variable and $g$ and $h$ denote the parameters relative to the coupling of damage and plasticity in the material.

By substituting Equations (14b) into (16), the relationship between the mean plastic variable $\mu_{\mathrm{r}}(\varepsilon)$ and total strain $\varepsilon$ is formulated as follows:

$$
\mu_{\mathrm{r}}(\varepsilon)=\frac{1}{\left[(g-h)+h /\left(1+\varepsilon / \varepsilon_{0}\right)^{p}\right]} .
$$

The standard deviation $\operatorname{STD}_{r}(\varepsilon)$ of the plastic variable $r(\varepsilon)$ is proposed by investigating on the experimental results displayed in Figure 4(b):

$$
\operatorname{STD}_{r}(\varepsilon)=H_{0}\left[\frac{A_{0}}{(w \sqrt{\pi / 2})}\right] \times \exp \left\{-2 \times\left[\frac{\left(\mu_{d r}-\mu_{0}\right)}{w}\right]^{2}\right\},
$$

where $H_{0}, A_{0}, w$, and $\mu_{0}$ denote the parameters relating to the variation of plasticity in the material due to the stochastic properties caused by the material's microstructures [25-27].

The detailed equations for the mean value of the plasticdamage variable $\mu_{d r}(\varepsilon)$, plastic variable $\mu_{r}(\varepsilon)$, and the standard variation $\operatorname{STD}_{r}(\varepsilon), \operatorname{STD}_{r}(\varepsilon)$ are obtained by fitting the experimental results, which can be evaluated as follows:

$$
\begin{aligned}
\mu_{d r}(\varepsilon) & =1-\frac{1}{(1+\varepsilon / 2101.48)^{5.078}} \\
\operatorname{STD}_{d r}(\varepsilon) & =0.0055+0.185 \cdot \exp \left[-\frac{1}{2} \times\left(\frac{\varepsilon-2212.15}{556.37}\right)^{2}\right],
\end{aligned}
$$

$$
\begin{aligned}
\mu_{r}(\varepsilon)= & \frac{1}{\left[1.127+4.948 /(1+\varepsilon / 2101.48)^{5.078}\right]}, \\
\operatorname{STD}_{r}(\varepsilon)= & 0.316 \times\left[\frac{0.118}{(0.298 \sqrt{\pi / 2})}\right] \\
& \times \exp \left\{-2 \times\left[\frac{\left(\mu_{d r}-0.343\right)}{0.298}\right]^{2}\right\} .
\end{aligned}
$$

Thus, a new stochastic constitutive model to characterize the stochastic constitutive relationship under both uniaxial monotonic and cyclic compression tests for SCC is developed.

3.3. Model Verification. In order to verify the effectiveness of the proposed model in this work, it has been validated by means of comparison with the experimental results for SCC obtained in this work.

Figure 5 shows the comparison results between the experimental results obtained from the uniaxial monotonic compression tests and the predictions in the view of the enveloping region (the blue region) among the eight stressstrain curves, the mean stress-strain curve, and its standard deviation curve. In Figure 5(a), it is shown that most of the stress-strain curves obtained from tests are located in the domain between the predicted mean + STD and mean STD curves of stress-strain relationships. In Figure 5(b), a very good matching between the predicted and experimental results of both the mean stress-strain curve and standard deviation curve is obtained. Nevertheless, the standard variation of stress predicted by the proposed model is found to be somewhat underestimated compared with the experimental result.

Figure 6 demonstrates the comparison results between the experimental results obtained from the uniaxial cyclic compression tests and the predictions on both the mean and standard deviation curves of $1 / r-d r$. In Figure $6(\mathrm{a})$, it is observed that most of the testing points are located in the domain between the predicted mean + STD and mean STD curves of $1 / r-d r$. In Figure $6(\mathrm{~b})$, it is revealed that, although there are some slight discrepancies, the standard deviations of $1 / r$ predicted by the proposed model give a good agreement with the experimental results.

In summary, by examining the comparison results between the predictions and the experimental results in this work, it is verified that the proposed model is able to characterize the stochastic constitutive relationship of SCC under both uniaxial monotonic and cyclic compression tests.

\section{Discussions}

4.1. Transition from Microscale to Macroscale. In this section, the causes for the stochastic mechanical behaviors for SCC in both the uniaxial monotonic and cyclic compression tests are further discussed by examining the media process of transition from microscale (microstructure) to the macroscale (macroresponse). The transition of stochastic microstructure 


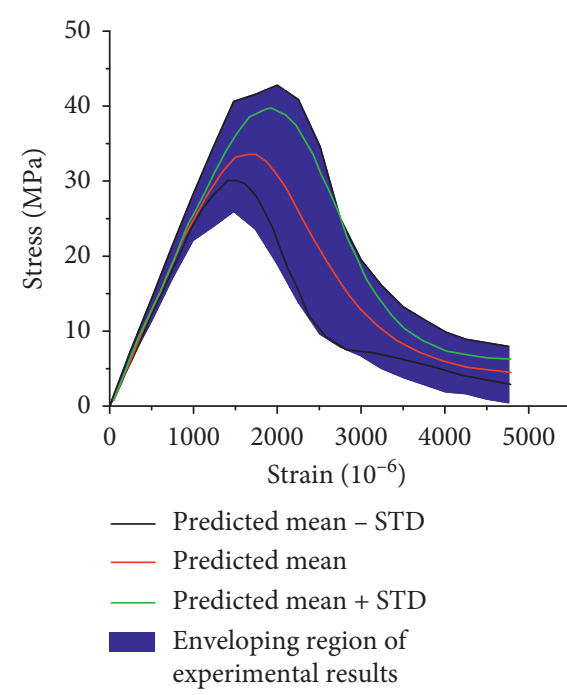

(a)

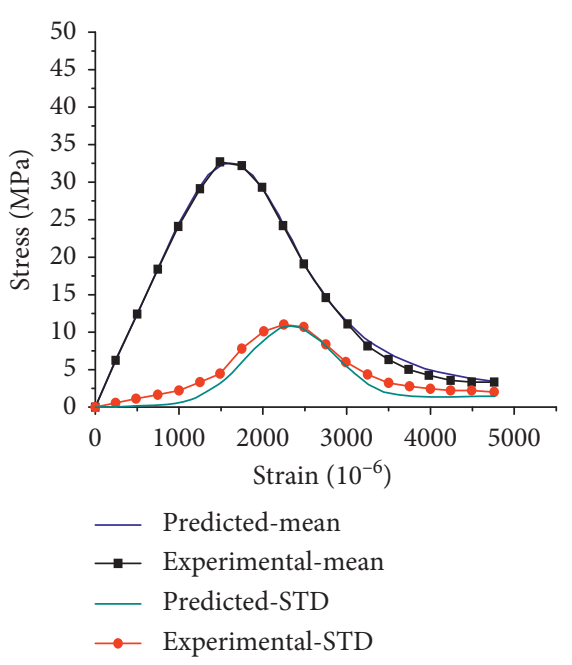

(b)

FIGURE 5: Comparison of experimental and predicted stochastic stress-strain response of SCC under uniaxial monotonic compression. (a) Enveloping region of $\sigma-\varepsilon$. (b) Mean and STD of $\sigma-\varepsilon$.

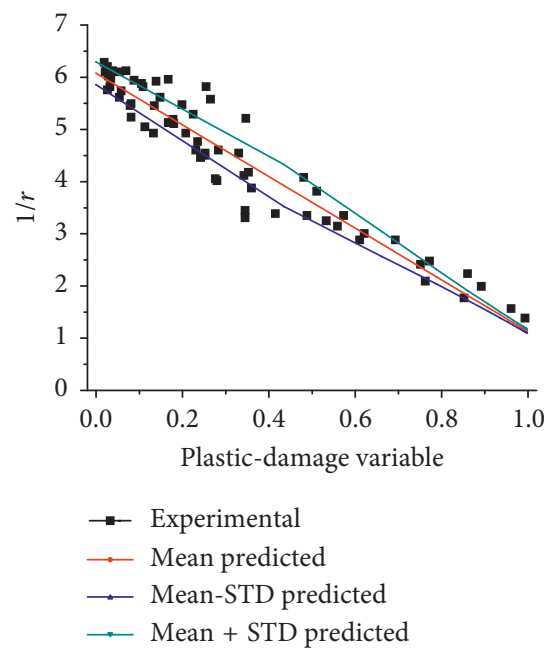

(a)

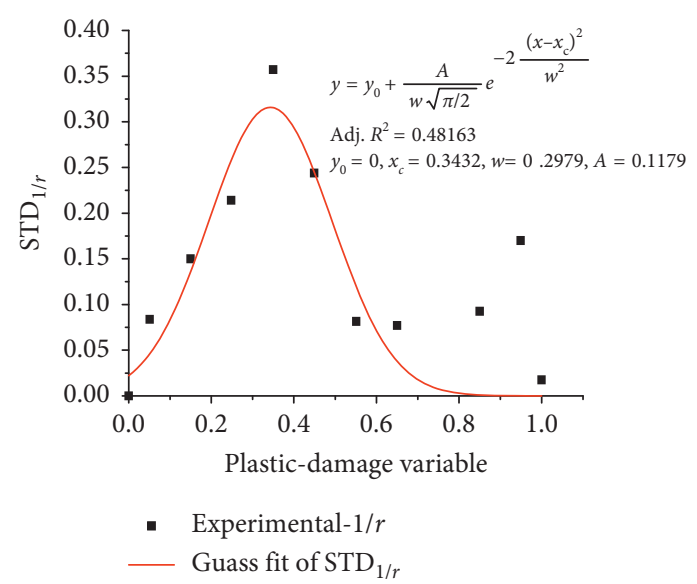

(b)

FIGURE 6: Comparison of experimental and predicted stochastic plasticity of SCC under uniaxial cyclic compression. (a) Experimental and predicted $1 / r$ vs. $d r$. (b) Experimental and predicted STD. ${ }_{1 / r}$ vs. $d r$.

to macroresponse of materials is generally an essential topic in the material and structural research field [19, 20, 25-29]. This topic involves the understanding of the inherent random nature for certain materials through different scales.

Figure 7 demonstrates the stochastic and the mean behaviors of the probability density of the damage-plastic variable $d r$ in the perspective of microscale. Specifically, in Figure 7(a), it is illustrated that for the SCC samples, different probability densities of the plastic-damage variable $d r$ are endowed and further resulted in different plasticity and damage developments during the loading process. The reasons for the occurrence of the stochastic probability densities can be attributed to the randomness of the initial microstructure for SCC samples.
In order to characterize the mean probability density of the plastic-damage variable $d r$, three commonly used density functions including the lognormal distribution, Gauss distribution, and Weibull distribution are adopted for fitting the data. The detailed results for fitting these three density functions are listed in Figures $7(\mathrm{~b})-7(\mathrm{~d})$, respectively. It is found the smallest value of the adjusted R-square occurs in Figure 7(b), which reveals that the lognormal distribution is in best agreement with the mean probability density of the plastic-damage variable $d r$.

Figure 8 illustrates the stochastic evolution (SE) of the plastic-damage variable $d r$ during the imposed uniaxial monotonic compressive loading history obtained from experimental results and the relative predictions by the 


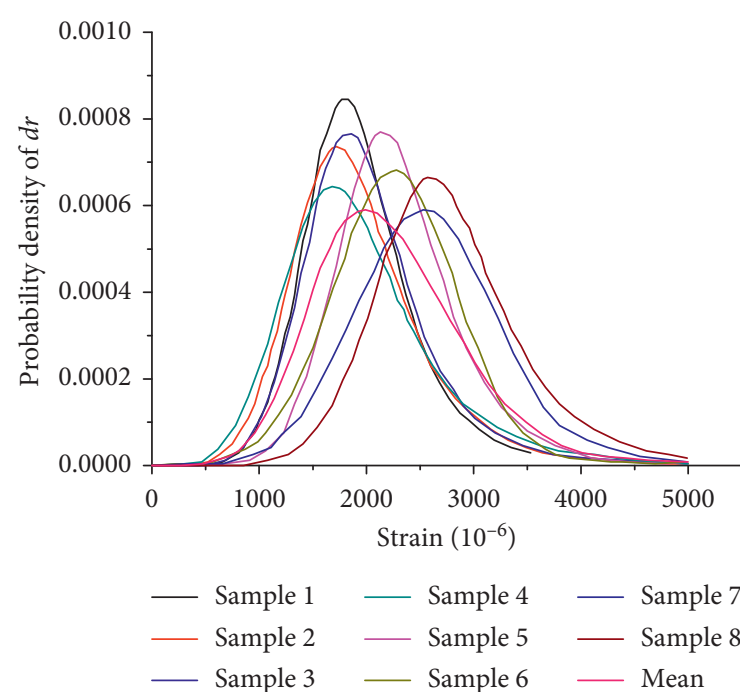

(a)

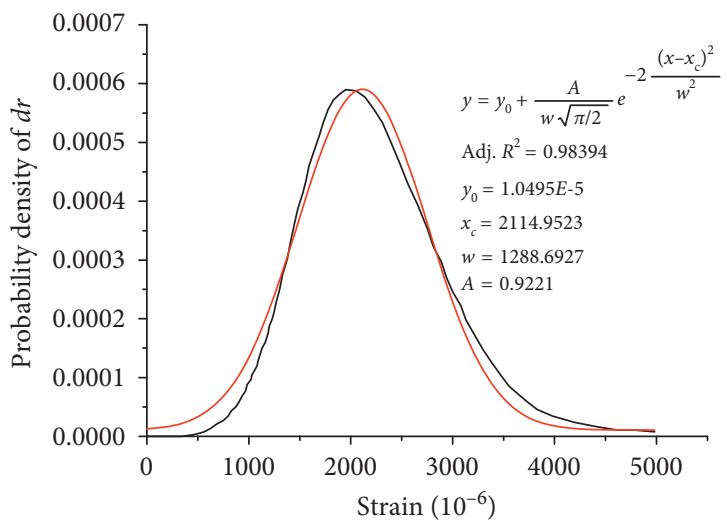

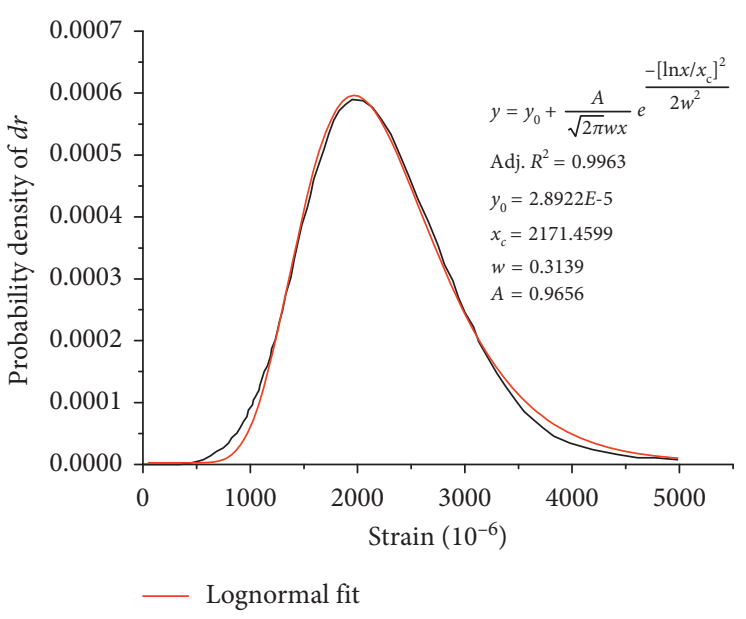

(b)

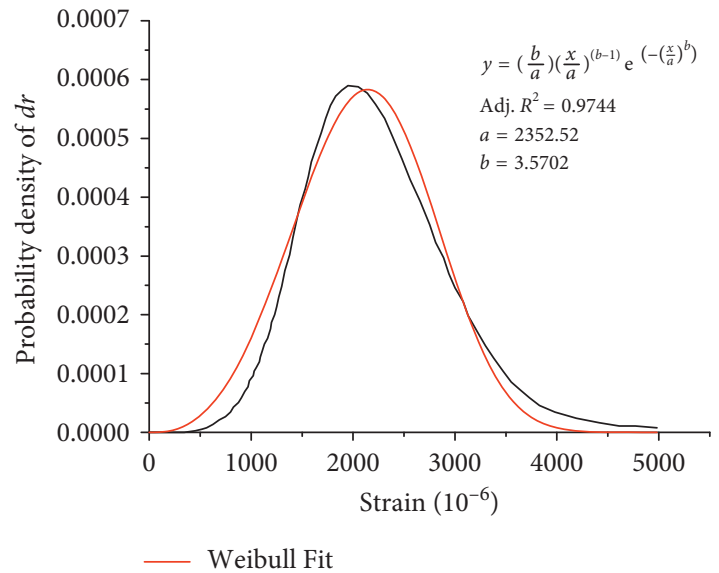

(d)

FIGURE 7: Stochastic probability density of micro-yield-damage thresholds of SCC samples under compression (a), and fitting of the mean probability density of the thresholds $(b-d)$.

proposed model. It is worthy to point out that the SE reflects the stochastic media process of transition from microscale (microstructure) to the macroscale (macroresponse) for SCC samples. Specifically, it is concluded that the SE of the plasticdamage variable $d r$ (Figure 8(a)) is caused by progressive accumulation of the plasticity and damage for SCC samples with different yield and damage thresholds (probability densities) displayed in Figure 7(a). By implementing Equations (19) and (20), the predicted mean and the standard deviation curves for the evolution of plastic-damage variable $d r$ are presented in Figure 8(b), which further demonstrates the media process of transition from microscale to macroscale for SCC samples under uniaxial monotonic loading: the stochastic probability densities of the plastic-damage variable $d r$ (Figure 7(a)) cause the SE of the plastic-damage variable $d r$ (Figure 8 ) and consequently result in the stochastic stressstrain relationships (Figure 3(a)).

Figures 9 and 10 illustrate the media process of transition from microscale (microstructure) to the macroscale (macroresponse) in terms of the plasticity and the elastic modulus reduction for SCC, by examining the SE of the plastic variable $r$ and the damage variable $d\left(\varepsilon_{\mathrm{E}}\right)$ in the elastic strain space $\left(\varepsilon_{\mathrm{E}}=\varepsilon-\varepsilon_{\mathrm{p}}\right)$. More precisely, by applying Equations (21) and (22), the SE of plastic variable $r$ is displayed in Figure 9(a), which further results in the stochastic development of the plasticity plotted in Figure 9(b). In Figure $10(\mathrm{a})$, the $\mathrm{SE}$ of the damage variable $d\left(\varepsilon_{\mathrm{E}}\right)$ is displayed by applying Equations (5)-(9) and Equations (14a)-(22), resulting in the stochastic degradation of elastic modulus plotted in Figure 10(b).

Therefore, the stochastic media process of transition from microscale (microstructure) to the macroscale (macroresponse) for SCC samples under both the uniaxial monotonic and cyclic compression tests is completely investigated. It is concluded that the stochastic mechanical behaviors of the SCC samples are caused by the stochastic probability density in the microscale (e.g., different microyield/damage thresholds), with the SE of the macrovariables 


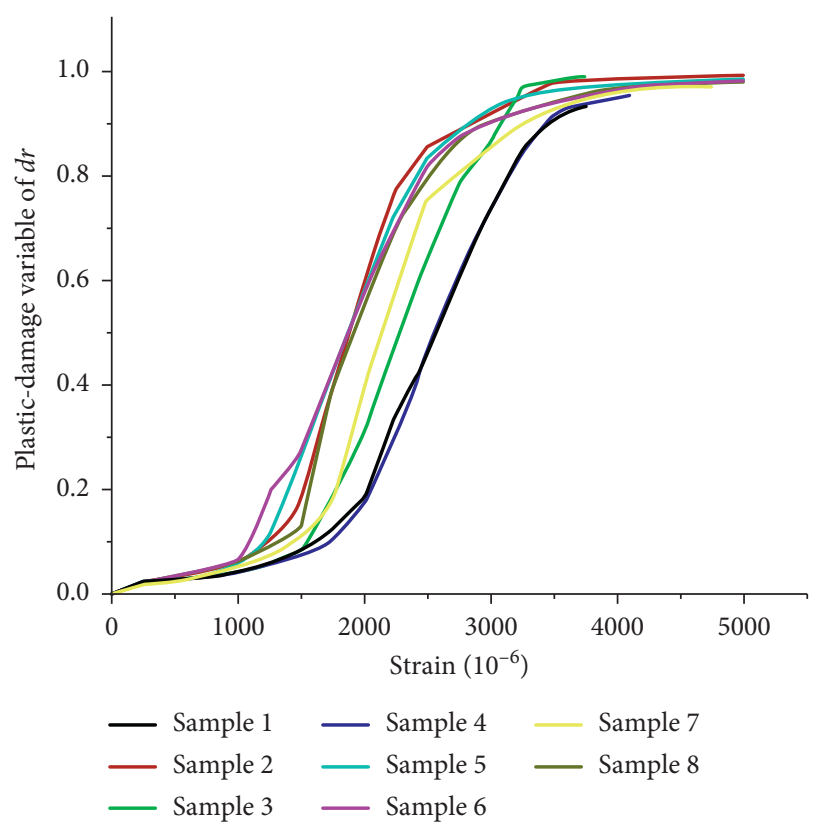

(a)

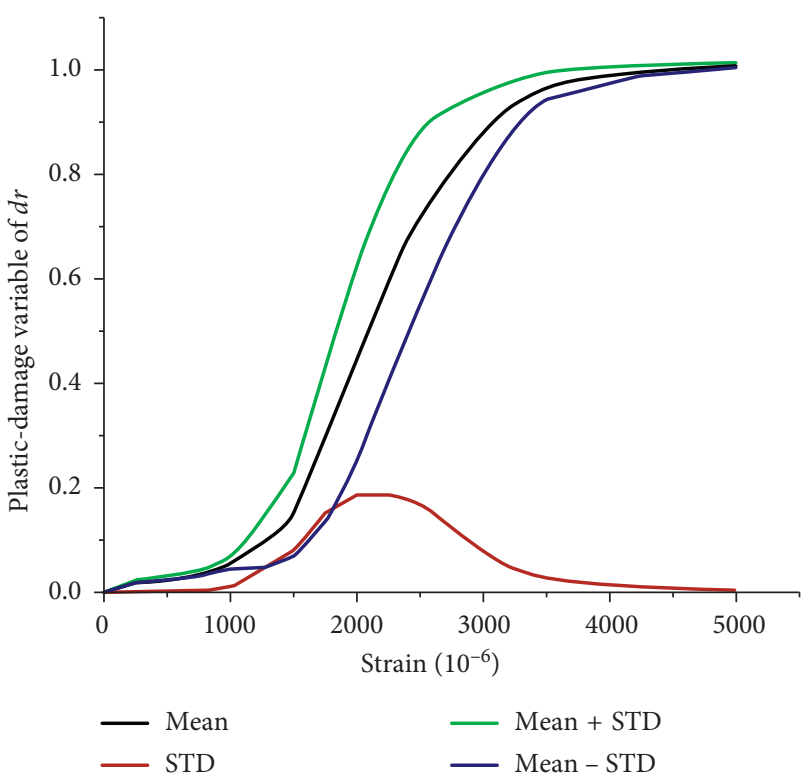

(b)

FIGURE 8: Experimental and predicted (mean and STD) evolution of the plastic-damage variable under compression. (a) Experimental evolution of $d r$. (b) Predicted evolution on mean and STD of $d r$.

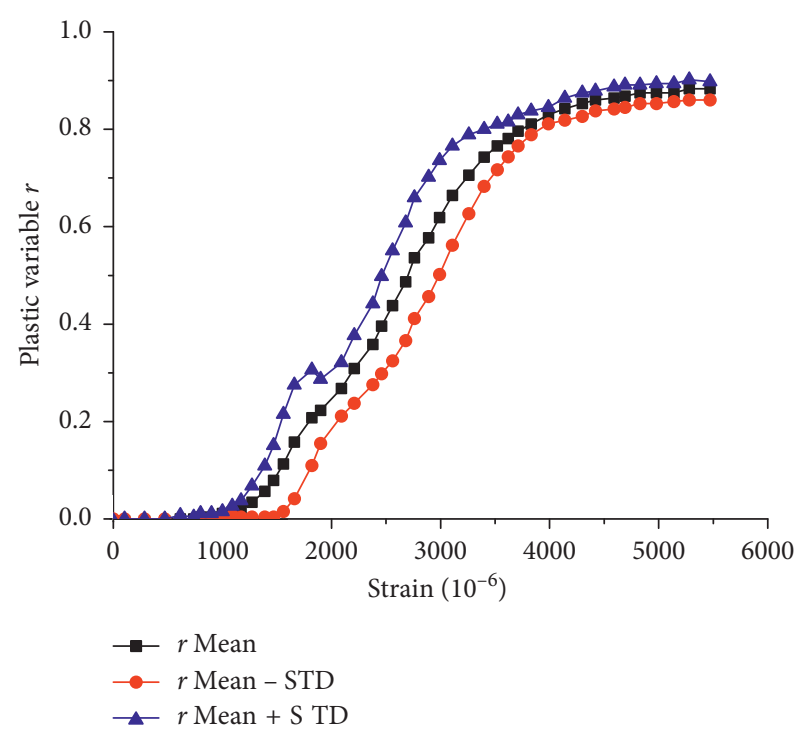

(a)

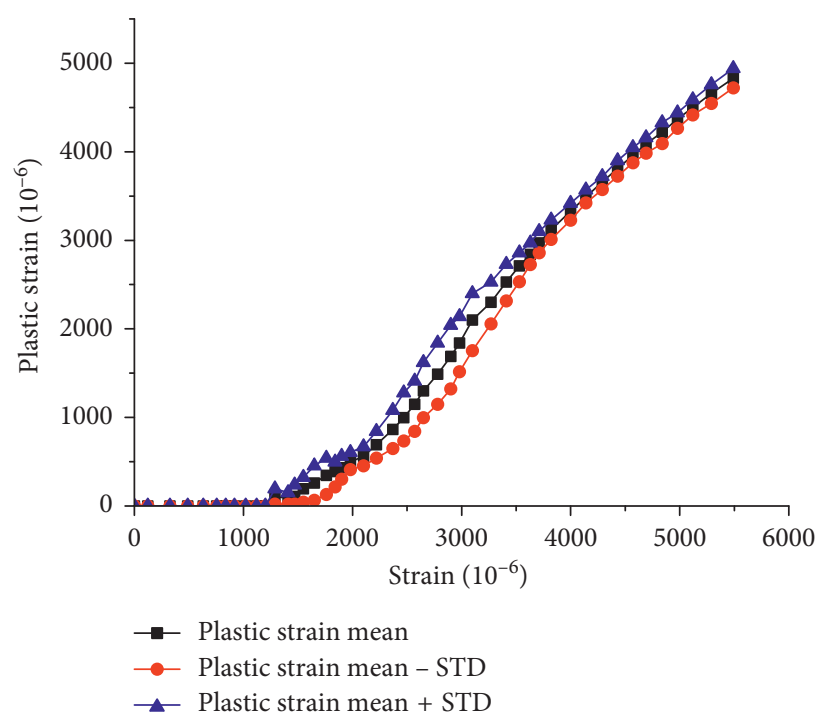

(b)

FIGURE 9: SE of plastic variable and plastic strains of SCC under compression obtained by the proposed model. (a) SE of plastic variable $r$. (b) Stochastic development of plastic strains.

(i.e., plastic-damage variable $d r$, plastic variable $r$, and damage variable $d\left(\varepsilon_{\mathrm{E}}\right)$ ) are considered as the media process of the transition.

4.2. Comparison of Constitutive Relationships between SCC and NVC under Compression. Comparisons of the mean constitutive relationships between SCC and NVC under compression is presented in this section, by examining on the evolution of the macrovariables mentioned in Section 4.1 and the relationships of $1 / r$ and $d r$. The comparisons are based on the experimental results of SCC in this work and the data provided by the literature $[19,29]$. The comparison results are plotted in Figures 11 and 12.

Figure 11 demonstrates the comparison results in terms of the plastic-damage probability density $P$ (Figure 11(a)), plastic-damage variable $d r$ (Figure 11(b)), and the stressstrain response obtained by normalization (Figure 11(c)) 


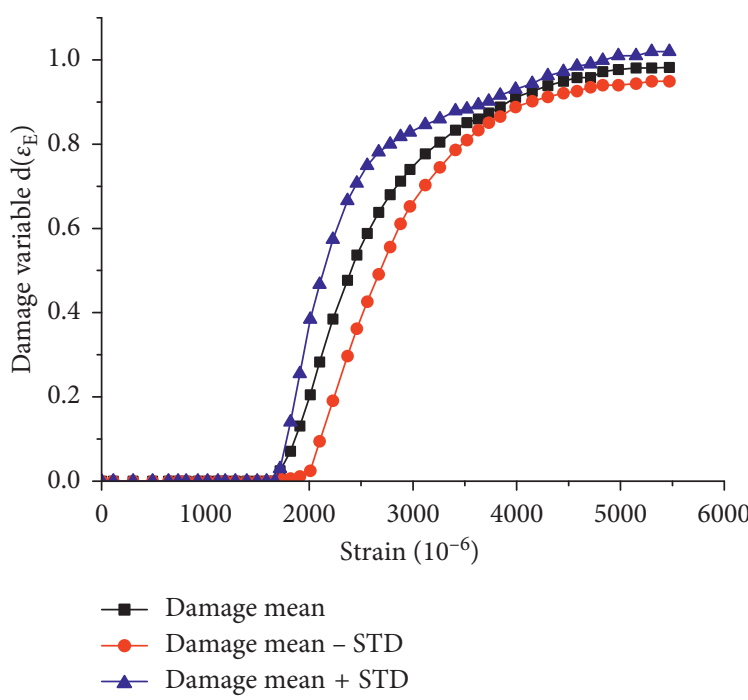

(a)

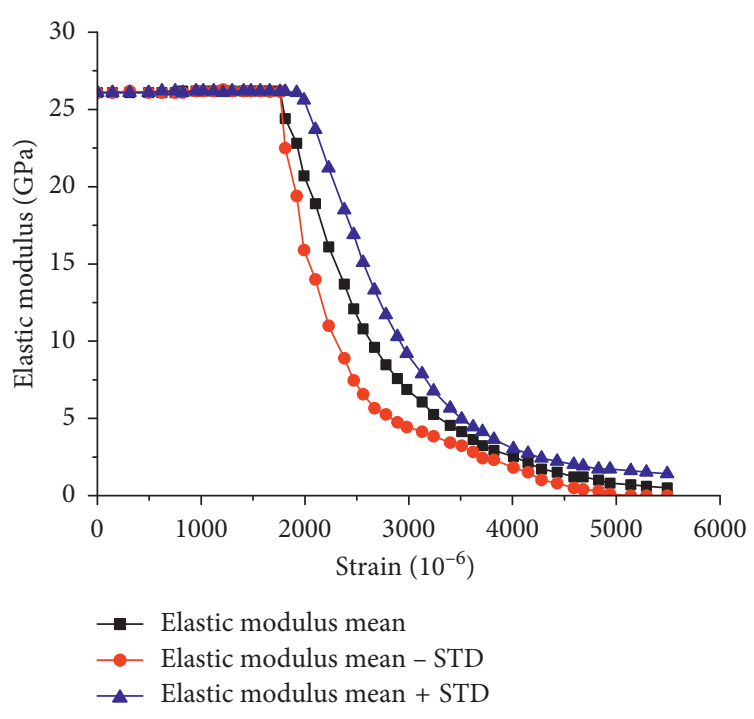

(b)

FIGURE 10: SE of damage variable $d\left(\varepsilon_{\mathrm{E}}\right)$ and elastic modulus degradation of SCC under compression (elastic strain $\varepsilon_{\mathrm{E}}=\varepsilon-\varepsilon_{\mathrm{p}}$ ) obtained by the proposed model. (a) SE of the damage variable $d\left(\varepsilon_{\mathrm{E}}\right)$ in the elastic strain space $\varepsilon_{\mathrm{E}}$. (b) Stochastic degradation of elastic modulus.

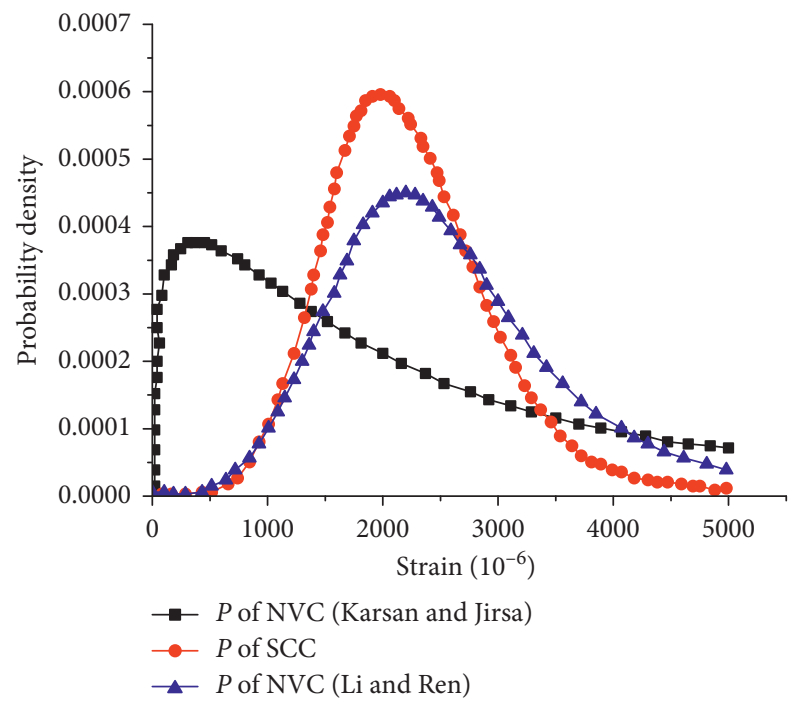

(a)

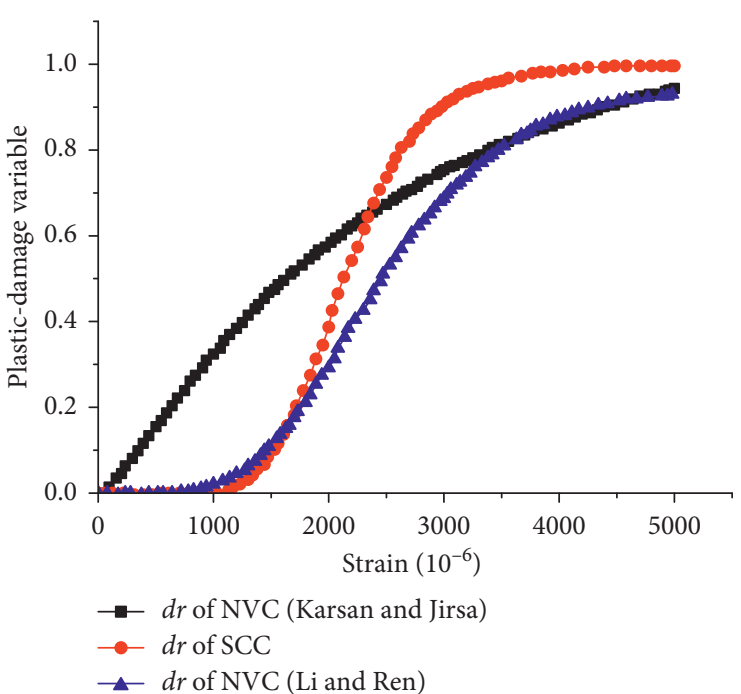

(b)

FIgURe 11: Continued. 


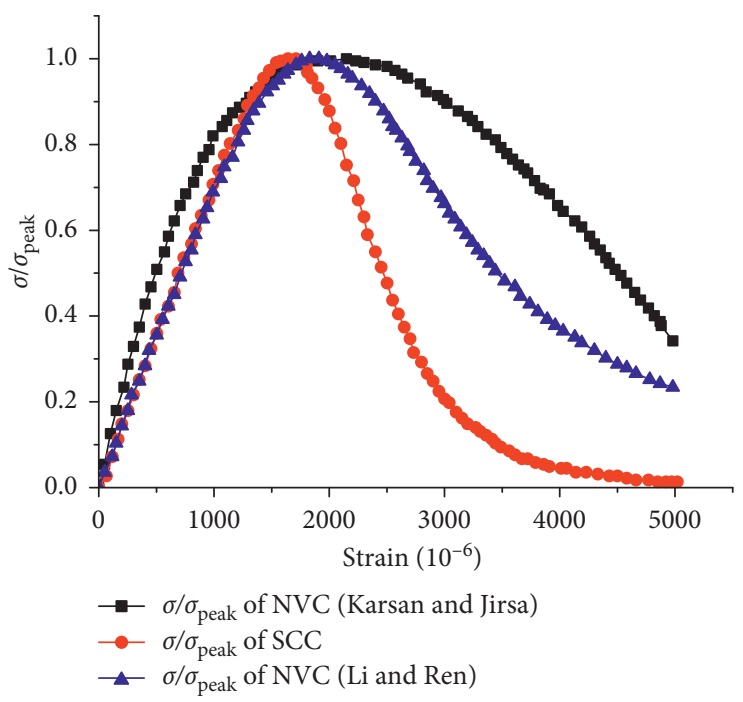

(c)

Figure 11: Comparison of the mean probability density P. (a) Probability density. (b) Plastic-damage variable $d r$. (c) Stress responses among SCC and two typical NVCs $[19,29]$ under compression.

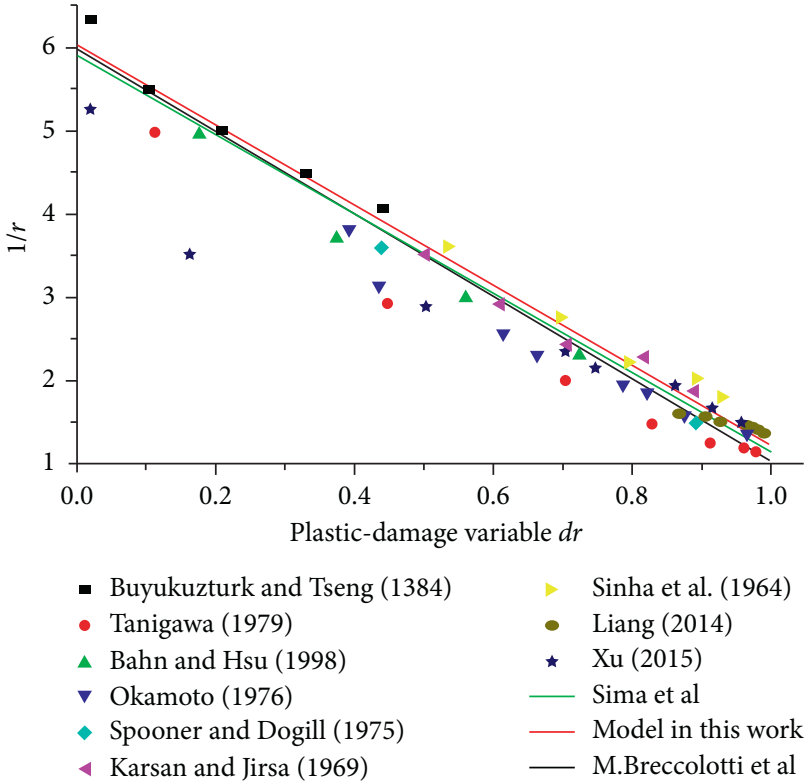

FIGURE 12: Comparison of $1 / r$ vs. $d r$ between SCC and typical NVCs $[23,24]$ under compression.

among SCC and typical NVCs analyzed in the literature $[19,29]$. Particularly, the largest peak value of $P$ in Figure 11(a) is observed in the curve of SCC, which further resulted in a steepest curve for the plastic-damage variable $d r$ of SCC. In addition, it is found that the shapes of the plastic-damage probability density $P$ curve have a significant influence on both the evolution of $d r$ and the stress-strain response. In detail, it is concluded that the lowest variation (i.e., the higher concentration) of the $P$ curve (SCC in Figure 11(a)) causes a most intensive development of $d r$ shown in SCC in Figure 11(b) and consequently leads to a most brittle stress-strain response (SCC in Figure 11(c)).
Figure 12 displays the relationship between $1 / r$ and $d r$ of SCC studied in this work and NVCs reported in the literature $[23,24]$. It is observed that the highest value of $1 / r$ (i.e., the slowest plasticity development) is produced by SCC during the whole loading process compared with that of NVCs. The reasons may be explained as the admixture and fly ash in SCC generate a relatively more homogeneous microstructure with a lower water accumulation around aggregated and porosity of ITZ than that of NVCs, due to the lack of vibration induced segregation $[5,14,18]$, further impedes the development of plasticity.

\section{Conclusions}

In this work, experimental investigations of SCC under uniaxial monotonic and cyclic compression were reported. By taking into account the stochastic constitutive relationship, an analytical model for describing the stressstrain response and plasticity of SCC was also proposed. The proposed model was developed based on the fiber bundleplastic chain model (BCM) [20] and a practical method for simulating the plasticity of the quasibrittle materials $[23,24]$. The validation of the proposed model was performed by comparison between the predictions and the experimental results. The comparison results revealed that the proposed model can effectively describe the stochastic constitutive relationship of SCC under both monotonic and cyclic compression tests.

Analysis on the media process of transition from microscale to macroscale for SCC was performed, and it was concluded that the stochastic constitutive relationship of SCC is caused by the randomness of the probability density in the microscale, and the stochastic evolution (SE) of certain variables in the macroscale are considered as the media process of the transition. 
Comparisons of the constitutive relationships with SCC studied in this work and NVCs reported in the literature $[19,23,24,29]$ revealed that the most brittle stress-strain response is obtained by SCC due to the lowest variation of the probability density curve. Additionally, it was also observed that SCC has the slowest plasticity development than NVCs, which can be attributed to the effects of the admixture and fly ash.

This work may be of significance for studying and modelling the stochastic constitutive relationship of SCC under uniaxial monotonic and cyclic compression and providing a better understanding and awareness of its uncertain effects on relevant engineering applications.

\section{Data Availability}

The data used to support the findings of this study are included within the article.

\section{Conflicts of Interest}

The authors declare that they have no conflicts of interest.

\section{Acknowledgments}

The studies presented here were developed within the research projects U1434204, 51808558, 51820105014, 51378506 , and 51478478 funded by the National Natural Science Foundation of China, whose assistance is gratefully acknowledged.

\section{References}

[1] N. Su, K. C. Hsu, and H. W. Chai, "A simple mix design method for self-compacting concrete," Cement and Concrete Research, vol. 31, no. 12, pp. 1799-1807, 2001.

[2] P. L. Domone, "Self-compacting concrete: an analysis of 11 years of case studies," Cement and Concrete Composites, vol. 28, no. 2, pp. 197-208, 2006.

[3] Z. Li, "State of workability design technology for fresh concrete in Japan," Cement and Concrete Research, vol. 37, no. 9, pp. 1308-1320, 2007.

[4] Z. Shan, Z. W. Yu, and J. J. Shi, "Experimental investigation of flow of fresh self-compacting concrete in improved L-box," Construction and Building Materials, vol. 84, pp. 30-38, 2015.

[5] P. L. Domone, "A review of the hardened mechanical properties of self-compacting concrete," Cement and Concrete Composites, vol. 29, no. 1, pp. 1-12, 2007.

[6] B. Persson, "A comparison between mechanical properties of self-compacting concrete and the corresponding properties of normal concrete," Cement and Concrete Research, vol. 31, no. 2, pp. 193-198, 2001.

[7] F. Aslani and S. Nejadi, "Mechanical properties of conventional and self-compacting concrete: an analytical study," Construction and Building Materials, vol. 36, pp. 330-347, 2012.

[8] S. Korte, V. Boel, W. De Corte, and G. De Schutter, "Static and fatigue fracture mechanics properties of self-compacting concrete using three-point bending tests and wedge- splitting tests," Construction and Building Materials, vol. 57, pp. 1-8, 2014.

[9] H. J. H. Brouwers and H. J. Radix, "Self-compacting concrete: theoretical and experimental study," Cement and Concrete Research, vol. 35, no. 11, pp. 2116-2136, 2005.

[10] F. M. A. Filho, B. E. Barragán, J. R. Casas, and A. L. H. C. El Debs, "Hardened properties of self-compacting concrete-a statistical approach," Construction and Building Materials, vol. 24, no. 9, pp. 1608-1615, 2010.

[11] EFNARC, Specifications and Guidelines for Self-Compacting Concrete, EFNARC, Farnham, Surrey, UK, 2002, http://www. efnarc.org/pdf/SandGforSCC.PDF.

[12] The Self-Compacting Concrete European Project Group (BIBM, CEMBUREAU, ERMCO, EFCA and EFNARC), The European Guidelines for Self-Compacting Concrete, 2005.

[13] Self-Compacting Concrete: A Review: Technical Report no. 62, The Concrete Society, UK; 2005, http://www.concrete.org. uk.

[14] A. S. El-Dieb, "Mechanical, durability and microstructural characteristics of ultra-high-strength self-compacting concrete incorporating steel fibers," Materials and Design, vol. 30, no. 10, pp. 4286-4292, 2009.

[15] A. Leemann, R. Loser, and B. Münch, "Influence of cement type on ITZ porosity and chloride resistance of selfcompacting concrete," Cement and Concrete Composites, vol. 32, no. 2, pp. 116-120, 2010.

[16] S. Aparicio, S. Martínez-Ramírez, J. Ranz, J. V. Fuente, and M. G. Hernández, "Microstructural and mechanical properties study of the curing process of self-compacting concrete," Materials and Design, vol. 94, pp. 479-486, 2016.

[17] M. C. Torrijos, B. E. Barragán, and R. L. Zerbino, "Physical-mechanical properties and mesostructure of plain and fibre reinforced self-compacting concrete," Construction and Building Materials, vol. 22, no. 8, pp. 1780-1788, 2008.

[18] A. Skarendahl and Ö. Petersson, "Self-compacting concretestate-of-the-art report," RILEM Report 23, Cachan Cedex, France, 2001.

[19] J. Li, J.-Y. Wu, and J.-B. Chen, Stochastic Damage Mechanics of Concrete Structures, Science Press, Beijing, China, 2014.

[20] Z. Shan and Z. Yu, "A fiber bundle-plastic chain model for quasi-brittle materials under uniaxial loading," Journal of Statistical Mechanics: Theory and Experiment, vol. 2015, no. 11, article P11010, 2015.

[21] Ministry of Housing, Development of the People's Republic of China Urban-Rural, PJGJ/T283-2012, Technical Specification for Application of Self-Compacting Concrete, China Architecture \& Building Press, Beijing, China, 2012.

[22] Ministry of Housing, Development of the People's Republic of China Urban-Rural, GB50152-2012, Standard for Test Method of Concrete Structures, China Architecture \& Building Press, Beijing, China, 2012.

[23] J. F. Sima, P. Roca, and C. Molins, "Cyclic constitutive model for concrete," Engineering Structures, vol. 30, no. 3, pp. 695-706, 2008.

[24] M. Breccolotti, M. F. Bonfigli, A. D’Alessandro, and A. L. Materazzi, "Constitutive modeling of plain concrete subjected to cyclic uniaxial compressive loading," Construction and Building Materials, vol. 94, no. 30, pp. 172-180, 2015.

[25] V. Berdichevsky, "On thermodynamics of crystal plasticity," Scripta Materialia, vol. 54, no. 5, pp. 711-716, 2006.

[26] Z. P. Bazant and S.-D. Pang, "Activation energy based extreme value statistics and size effect in brittle and quasibrittle fracture," Journal of the Mechanics and Physics of Solids, vol. 55, no. 1, pp. 91-131, 2007. 
[27] H. Askari, M. R. Maughan, N. Abdolrahin, D. Sagapuram, D. F. Bahr, and H. M. Zbib, "A stochastic crystal plasticity framework for deformation of micro-scale polycrystalline materials," International Journal of Plasticity, vol. 68, pp. 21-33, 2015.

[28] X. L. Yang and Q. J. Pan, "Three dimensional seismic and static stability of rock slopes," Geomechanics and Engineering, vol. 8, no. 1, pp. 97-111, 2015.

[29] I. D. Karsan and J. O. Jirsa, "Behavior of concrete under compressive loadings," Journal of the Structural Division, vol. 95, no. 12, pp. 2535-2563, 1969. 


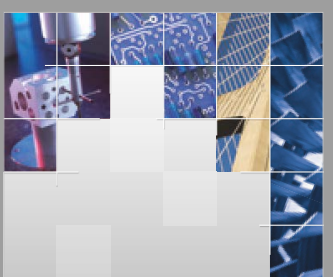

\section{Enfincering}
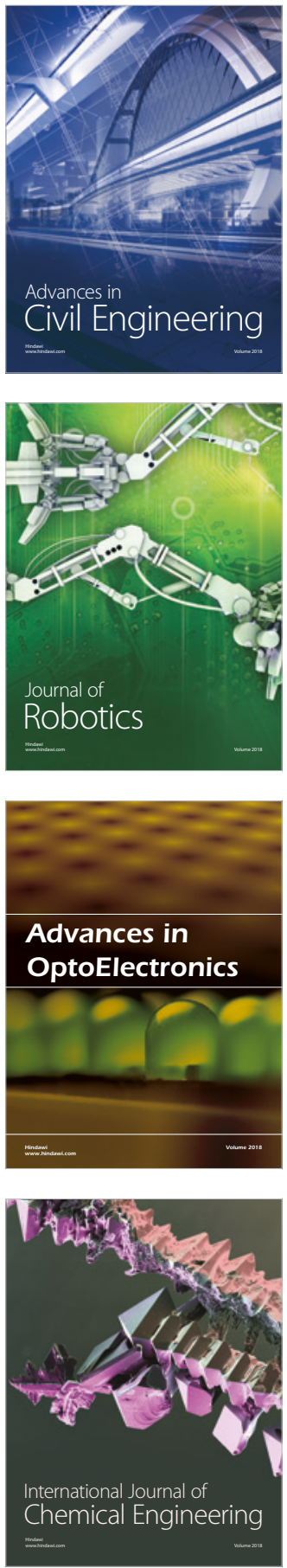

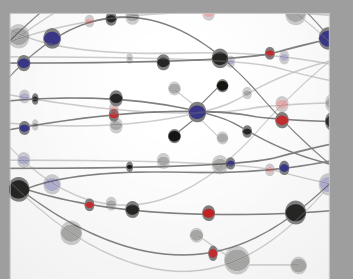

\section{Rotating \\ Machinery}

The Scientific World Journal

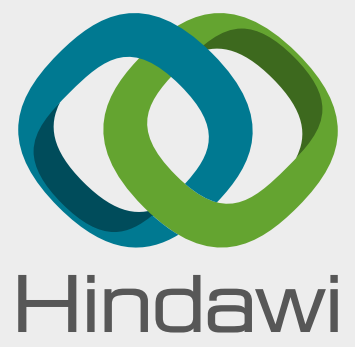

Submit your manuscripts at

www.hindawi.com
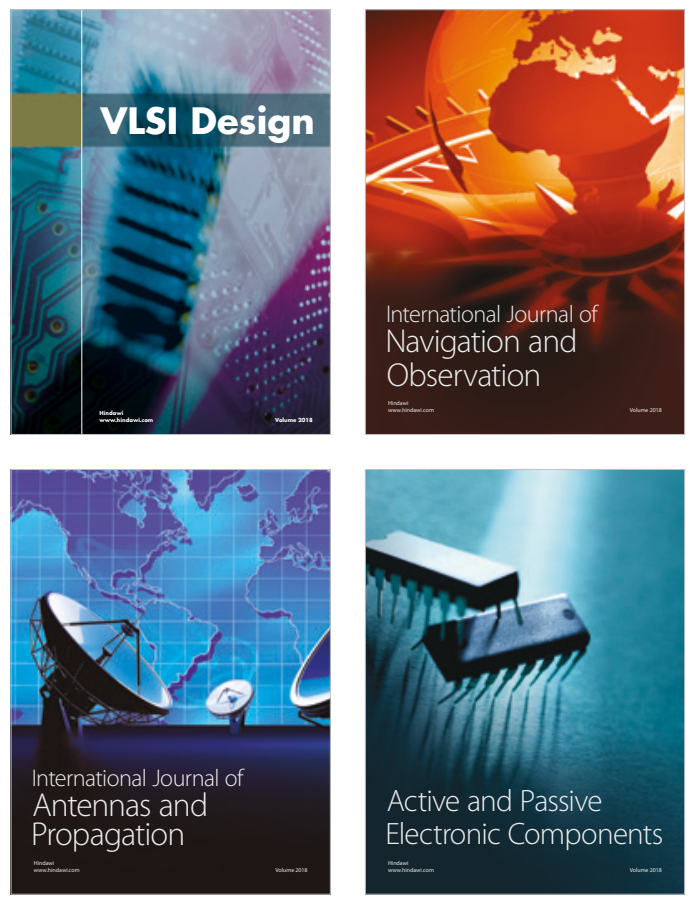
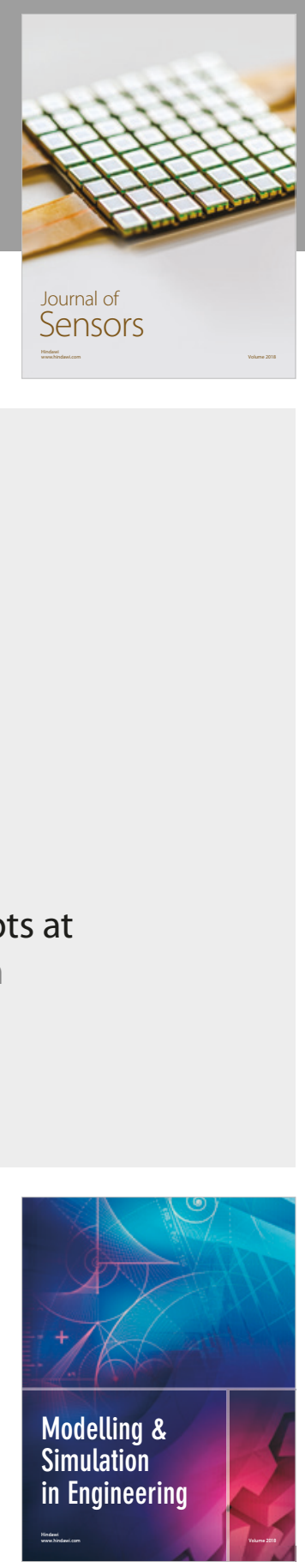

\section{Advances \\ Multimedia}
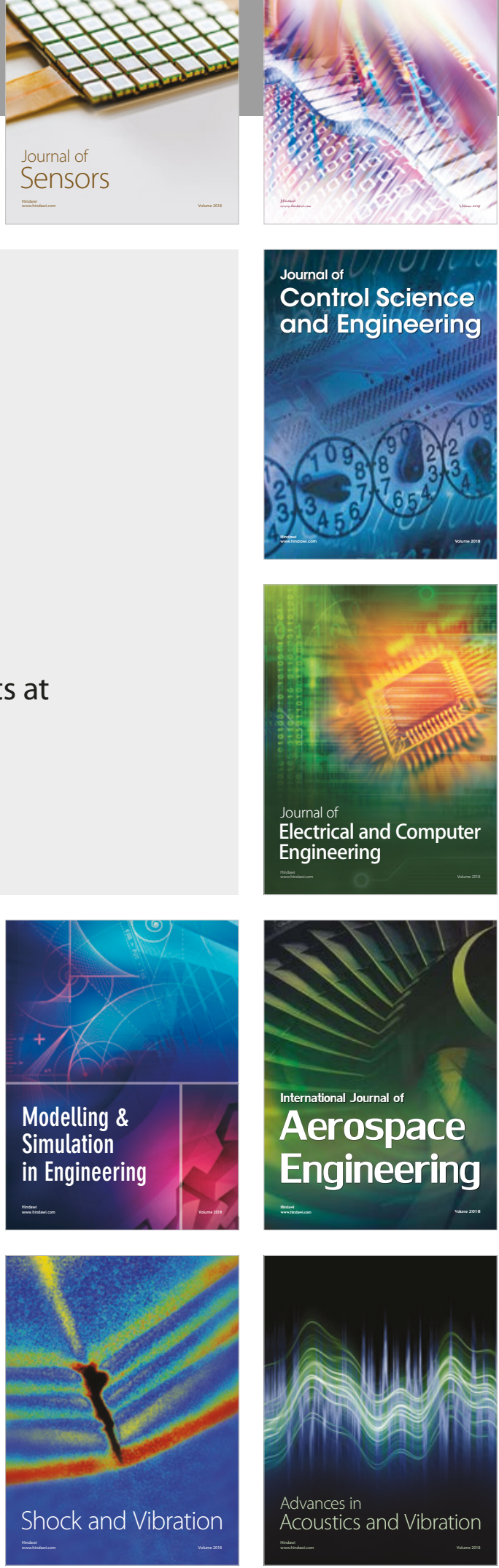